Volume (3) No. (1) 2020

الحاجات التدريبية المعرفية لمعلمي العلوم بالمرحلة المتوسطة في ضوء مصفوفة المدى والتتابع لمناهج العلوم المطورة

عبداللطيف بن سعد علي المالكي 
الحاجات التدريبية المعرفية لمعلمي العلوم بالمرحلة المتوسطة في ضوء مصفوفة المدى والتتابع

$$
\begin{aligned}
& \text { لمناهج العلوم المطورة } \\
& \text { عبداللطيف بن سعد علي المالكي } \\
& \text { ماجستير مناهج وطرق تدريس العلوم، السعودية } \\
& \text { abo_lama2002@hotmail.com }
\end{aligned}
$$

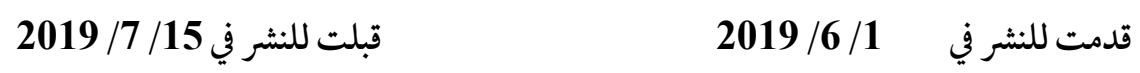

المستخلص: هدفت هذه لدراسة المى تحديد الحاجات التدريبية المعرفية لمعلمي العلوم بالمرحلة

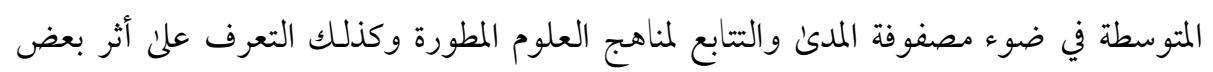
المتغيرات وهي: طبيعة العمل، والخبرة في التدريس ولتحقيق هذه الاهداف استخدم الباحث الاستبانة لقياس الحاجات التدريبية المعرفية لمعلمي العلوم حيث بلغ مجتمع الدراسة (140) معلم و

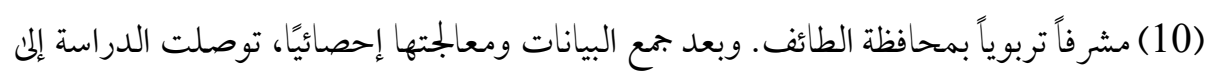
النتائج الآتية: هنالك حاجة إلى تدريب معلمي العلوم بالمرحلة المتوسطة في ضوء مصفوفة المدىن والتتابع لمناهج العلوم المطورة في بعض المعارف و المحتويات بدرجة كبيرة، وفي البعض الآخر بدرجة متوسطة. إن الحاجة إلى تدريب معلمي العلوم بالمرحلة المتوسطة علن معارف ومحتويات محور العلم و التقنية والمجتمع تأتي في المرتبة الأولى حيث يليها محوري علم الأرض والعلوم الطبيعية في المرتبة الثانية ثم محور الاستقصاء العلمي وأخيراً محور علم الحياة. وقد اوصت الدراسة بضرورة إعادة النظر في برامج تدريب معلمي العلوم بالمرحلة المتوسطة لتغطية الجموانب المعرفية لمناهج العلوم المطورة في ضوء مصفوفة المدئ والتتابع والاهتحام بالمعارف والمحتويات الحديثة في مناهج العلوم المطورة لمحاور: العلم والتقنية والمجتمع والعلوم الطبيعية وعلم الأرض وإدراجها ضمن برنامج تدريب معلمي العلوم بالمرحلة المتوسطة.

الكلمات الدلالية: الحاجات المعرفية، التدريب، المرحلة المتوسطة، مصفوفة المدئ والتتابع، مناهج

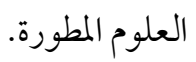




\title{
Knowledge Training Needs for Science Teachers of Intermediate Stage in the Light of Scope and Sequence Matrix of Science Developed Curricula
}

\author{
Abdullatif saad ali al-malki \\ Master of Curricula and Methods of Teaching Science, Saudi Arabia, \\ abo_lama2002@hotmail.com
}

Received in 1st June 2019

Accepted in 15th July 2019

\begin{abstract}
This study aimed to identify the cognitive training needs of science teachers in the intermediate stage in the light of the range and sequencing matrix of the developed science curricula, as well as to identify the effect of some variables: the nature of the work, the experience in teaching and to achieve these objectives The researcher used the questionnaire to measure the cognitive training needs of science teachers, (140) teachers and (10) educational supervisor in Taif province. After collecting and processing the data statistically, the study reached the following results: There is a need to train science teachers in the intermediate stage in the light of the range and sequence matrix of science curricula developed in some knowledge and content to a large degree, and in others to a medium degree. The need to train science teachers in the intermediate stage on the knowledge and contents of the axis of science and technology and society comes first, followed by the pivotal science of the earth and natural sciences in second place, then the focus of scientific inquiry, and finally the axis of life science. The study recommended the need to review the training programs of science teachers in the middle stage to cover the cognitive aspects of the curricula of science developed in the light of the matrix of the range and sequencing and interest in knowledge and contents in modern science curricula developed for the axes: science, technology, society, natural sciences and earth science, and included in the program of training science teachers in the middle stage.
\end{abstract}

Keywords: cognitive needs, training, intermediate stage, sequence and sequence matrix, developed science curricula. 


\section{Summary:}

The Ministry of Education in the Kingdom of Saudi Arabia seeks to develop the performance of teachers through the training programs provided to them in order to contribute to raising their cognitive and educational competence, to be consistent with the needs of the educational curricula and its contents and the developments that accompany them. According to the ministry's work on the science and mathematics project for the developed curriculum, it became necessary to possess the science teachers of the necessary knowledge and skills to help them cope with this development in order to raise the level of absorption and achievement of students in the science and achievement of educational Objectives.

This study aims to identify the cognitive training needs of science teachers in the intermediate stage in light of the developed curricula in the Kingdom of Saudi Arabia by answering the main question:

What are the cognitive training needs of science teachers in the light of the range and sequence matrix of developed science curricula?

The aim of this study is to identify the cognitive training needs of science teachers in the intermediate stage in the light of the range and sequencing matrix of developed science curricula and to identify the effect of some variables (nature of work, experience in teaching).

The researcher used a questionnaire to measure the cognitive training needs of science teachers in the intermediate stage in the light of the range and sequencing matrix of developed science curricula, divided into five axes: (biology, earth science, natural sciences, scientific inquiry, science, technology and society). The need to train science teachers in the intermediate stage on the knowledge and contents of the axis of science and technology and society comes first, followed by the pivotal science of the earth and natural sciences in second place, then the focus of scientific inquiry, and finally the axis of life science. 


\section{مقدمة - مق مق}

تقدم الامم ومو اكبتها للتغيرات المتسار عة في مجالات المعرفة والثقافية والتقنية والاقتصـادية-

يتطلب في المقابل سرعة في التنمية البشرية وهي في حقيقتها تنمية القدرات والكفاءات لتواكـب تلـك المتغيرات. ويُعد التدريب عاملاً هاماً في زيادة ورفع الكفاءات والقدرات البشرية والتي تمثل إحـدىن الأهداف الرئيسية للتنمية حيث تهتم غالبية دول العالم بالتدريب وإن اختلفت درجات هذا الاهـتمام بين العالم المتقدم، والعالم الذي يقف علن أبواب التقدم، والعاله النامي، فمعظم الدول أصبحت تعي أهميـة التـدريب لمـالـهـ مـن دور فعـال في المحافظـة عـلن مكتسـباتها الحـاليـة، والمســاعدة في تحقيـق استراتيجياتها المستقبلية (Colman, 2003)

ونظرًا لأهمية العنصر البشري في التنمية، وانسجامًا مع تطلعاتها المستقبلية، أحدثت المملكـة العربية السعودية تطويرًا ملموسًا على مناهج الرياضيات والعلوم، تمثّل في مشروع تطوير الرياضيات و العلوم الذي يستند إلمى معايير عالمية ويرتكز علن آخر ما توصلت إليه الأبحاث في هذا المجال، حيث تم اختيار واحدة من السلاسل العالمية وهي "سلسلة ماجروهل الأمريكية/ McGraw-Hill " للعلـوم والرياضيات والتي أثبتت جودتها وقدرتها علن تحسين العمليـة التعليميـة في العديـد مـن الولايـات الأمريكية وفي العديد من الدول الأخرى التي تتخذ من هذه السلسة منهجاً معتمداً للتعليم العام في كافة مدارسها. ويهدف هذا المشروع ع إلى: إعداد جيل من المبدعين والمبتكرين السعوديين الذين يمكنهم توظيف العلوم والرياضيات والذي اشتمل علن تنمية أداء المعلمين والمشرفين، في نقل التكنولوجيا وتطبيقاتها. الاستفادة من التطور التقني والتربوي الذي توفره بيوت الخبرة العالمية المتتجة للمواد

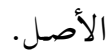
توطين صناعة وإنتاج المواد التعليمية. التطوير المهني المستمر لمعلمي العلوم والرياضيات (الرومي، 2009م) 
وقد أشارت دراسة العسبلي (2010م) إلى سعي وزارة التربية والتعليم في المملكة العربية السعودية إلى تطوير أداء المعلمين من خلال البرامج التدريبية التي تُقدم لهم كي تساهم في رفع كفاءتهم المعرفية والتربوية، لتتسق مع احتياجات المناهج التربوية ومحتواها، والتطورات التي

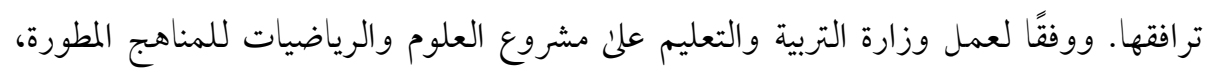
أصبح من الضروري امتلاك معلمي العلوم لمعارف ومهارات ضرورية تساعدهم على مو اكبة هذا التطور وذلك من أجل رفع مستون استيعاب وتحصيل الطلاب في مادة العلوم وتحقيق أهدافها التربوية ليتسنى لهم منافسة أقرانهم علن المستوى العلمي. وأفرز مشروع العلوم والرياضيات حاجات تدريبية أملتها المناهج الجديدة، التي تضمنت الحديث من المعرفة والتقنية العلمية، مما دعا بوزارة التربية والتعليم إلى عقد برامج تدريبية خلال العام الدراسي، إلا أن العديد من الدراسات التي

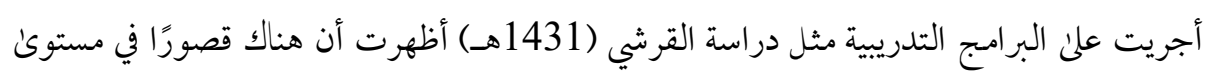
الكفايات التربوية والمعرفية لدىن معظم المعلمين بسبب قصور برامج التدريب المستمر للمعلم أثناء الخدمة في تلبية حاجات المعلمين. وتبرز أهمية تحديد الحاجات التدريبية الفعلية بغية الوقوف علن النواحي الهامة التي يجتاجها معلمو العلوم في عملهم لضمان تصميم البرامج التدريبية ذات الصلة المباشرة لمتطلبات مناهج العلوم المطورة، والتي تساعد على رفع الأداء التدريسي للمعلمين، واستثمار الجههد والمال الذي يبذل على البرامج التدريبية بأفضل صورة ممكنة.

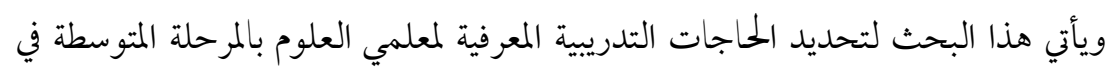
ضوء المناهج المطورة بالمملكة العربية السعودية. مشكلة الدراسة: - n إن كفاءة أي مؤسسة تعليمية وجودة ما تقدمه من تعليم وما تحققه من مستوكن تعليمي لخريجيها تقاس بكفاءة معلميها وما يمتلكونه من مهارات فالمعلم هو القائم علن تنفيذ المنهج لذلك 
يجب تدريبه وتأهيله بصورة مستمرة في ضوء المناهج المطورة. لذا تُعد قضية تدريب المعلمين من القضايا التي تمثل الصدارة بين مشروعات التطوير التربوي في المؤسسات التعليمية. وهناك حقيقة ثابتة في مجال التدريب مفادها أن فعالية تخطيط البرامج التدريبية وتصميمها وتنفيذها وتقويمها تعتمد أساساً على تحديد الاحتياجات التدريبية حيث أن عملية تحديد الاحتياجات التدريبية يترتب عليها تقرير نوعية التدريب المطلوبة ومن يحتاج اليها ومستوى الخبرة المطلوب تحقيقه لدئ المتدربين (عبدالسلام 2007م) بعد مراجعة الادبيات والدراسات السابقة اتضح للباحث الحاجة المي دراسة الحاجات التدريبة المعرفية لمعلمي العلوم في ضوء مصفوفة المدىن والتتابع للمر حلة المتوسطة وذلك لعدم وجود دراسة تناولت هذه الحاجات حيث ركزت الدراسات السابقة على الاحتياجات التدريبية في مجال اكتشاف الموهوبين أو في المجال التقني كاستخدام الوسائل التعليمية أو في ضوء معايير الجودة والاعتماد أو في مواد اخرى كالرياضيات ولم يمد الباحث علن حد علمه دراسة تناولت الحلاجات التدريبية المعرفية لمعلمي العلوم. ومن هنا برزت الحاجة هذه الدراسة ومن امثلة هذه الدراسات: ما أشارت إليه نتائج بعض الدراسات مثل دراسة منيرة الفهيد (1419هـ) ودراسة الشهري (1422هـ) إلى أن تدريس العلوم في المرحلة المتوسطة في المملكة العربية

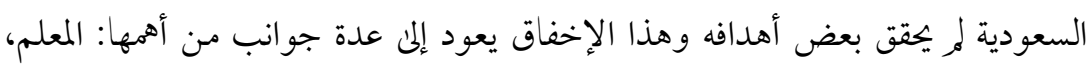
وجاء في توصيات تلك الدراسات التأكيد علن قيام برامج تدريبية قائمة علن الحاجات الفعلية للمعلمين. أظهرت نتائج تحليل الباحث للحقائب التدريبية المصاحبة لمشروع تعليم العلوم والرياضيات، أنها لم تتناول الجانب المعرفي للمحتوى وله تقدم أي تنشيط معرفي يتعلق بالموضوعات المستجدة في المناهج المطور. 
الاطلاع علن سجل زيارات المشرفين التربويين للمدارس وما ورد فيه من توصيات حيث يوصي المشرف التربوي بالاهتمام بالطرائق التدريسية ومراعاة الفروق الفردية واستخدام

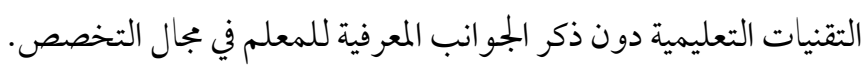
الاطلاع على تصنيف بيرسون للتعليم (Pearson 2013) القائم علن مؤشرات المهارات المعرفية والتحصيل العلمي ويستند هذا التصنيف الحديث علي سلسلة من نتائج الاختبارات العالمية وإجراءات تتعلق بنظم التعليم، والثقافة العامة للدولة مثل عدد الأشخاص الذين يذهبون إلى التعليم الجامعي ومكانة المعلم التي يتمتع بها داخل هذه الدول، وتعتمد هذه المقارنات علي الاختبارات التي تؤخذ للتقييم كل ثلاثة أعوام، وفي بجالات محددة مثل الرياضيات، والعلوم، حيث تصدرت القائمة دولة فنلندا ثم تلتها كوريا http: //www.pearson.com الشمالية ولم ترد أي من الدول العربية في قائمة الاربعين دولة الاطلاع علن الخطة العامة للتدريب التربوي حيث شملت الخطة تدريب معلمي العلوم علن. طرائق التدريس كالتعلم النشط والتدريس المتمايز، والتقويم المتمركز حول المتعلم ولمتورد الخطة أي دورات تدريبية في بجال المعرفة.

وبناءً على ما سبق ذكره، استشعر الباحث الحاجة لدراسة تستهدف تحديد الحاجات التدريبية المعرفية لمعلمي العلوم بالمرحلة المتوسطة في ضوء مصفوفة المدى والتتابع لمناهج العلوم المطورة. حدود الدراسة :

الحدود الموضوعية: تقصي الحاجات التدريبية المعرفية الفعلية لمعلمي العلوم بالمرحلة المتوسطة في ضوء مصفوفة المدىن والتتابع لمناهج العلوم المطورة.

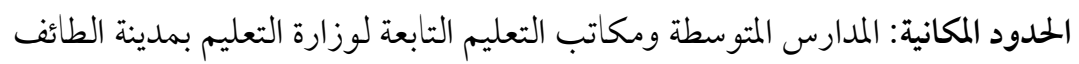
الحدود البشرية: معلمي مادة العلوم بالمرحلة المتوسطة والمشرفين التربويين. تكوّنت عينة الدراسة من جميع افر اد مجتمع الدراسة وعددهم (158) معلماً و (10) مشرفاً

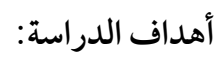


تحديد الحاجات التدريبية المعرفية لمعلمي العلوم بالمر حلة المتوسطة في ضوء مصفوفة المدىن

$$
\text { والتتابع لمناهج العلوم المطورة. }
$$

التعرف علن تأثير بعض المتغيرات وهي طبيعة العمل، والخبرة في التدريس في تحديد الحاجات التدريبية المعرفية لأفراد العينة.

حاجات المعلمين من المعارف والمهارات في ضوء معايير محتوكئ منهج العلوم لفهم بناء المادة التعليمية بحيث يتضمن فهمه و إدر اكه المفاهيم والمهارات الأساسية التي تصف وتحدد المادة والطرق التي ترتبط بها هذه المفاهيم والمهارات معاً.

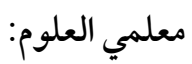
كل معلم يممل مؤهلاً جامعياً لا يقل عن البكالوريوس (تخصص علمي) ويقوم بتدريس مادة العلوم في المرحلة المتوسطة. المرحلة المتوسطة (الإعدادية):

المرحلة التي تلي المرحلة الابتدائية وتسبق المرحلة الثانوية ومدتها ثلاث سنوات، وتعادل المستوك من السابع إلى التاسع في بعض الدول. مصفوفة المدى والتتابع: General scope \& sequence جدول من بعدين تتضمن قائمة بمحتويات المعارف والمفاهيم والتعميات والمهارات العلمية يمثل البعد الأول الأفقي (بُعد المحتوىن) :علم الحياة، وعلم الارض، والعلوم الطبيعية (فيزياء كيمياء)، و الاستقصاء العلمي والعلم والتقنية والمجتمع، ويمثل التسلسل للمحتوئ العلمي 
عبر الصفوف من حيث العمق العلمي والتوسع، والبعد الثاني الرأسي) بُعد الصف) :الصف الأول

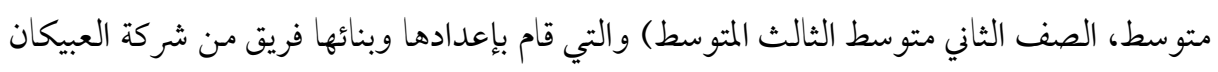

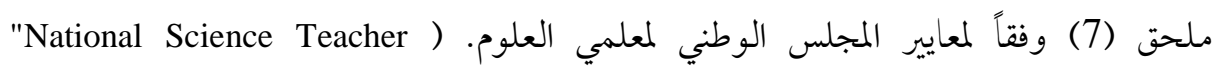
.Association"(NSTA

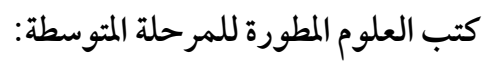

هي كتب العلوم الجديدة التي تمت مو اءمتها في ضوء سلسلة ماجروهل التعليمية والتئي

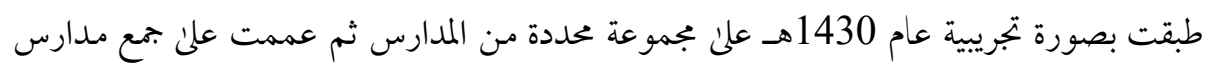

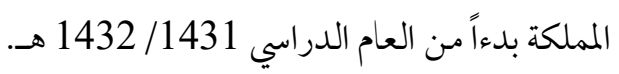
أسئلة الدراسة: 1. ما الحاجات التدريبية المعرفية لمعلمي العلوم في ضوء مصفوفة المدئ والتتابع لمناهج العلوم المطورة؟

2. هل تختلف الحاجات التدريبية المعرفية باختلاف طبيعة العمل؟

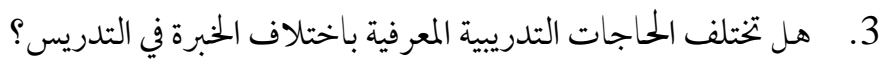
موضوعات الإطار النظري: مشروع تطوير العلوم: موطري

ويسعئ مشروع تطوير العلوم من خلال برابهه إلى إكساب الطلاب والطالبات المهارات

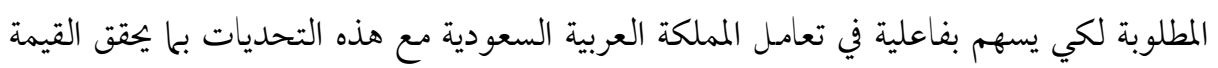

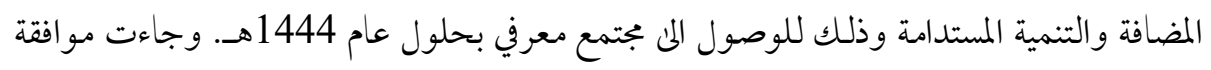

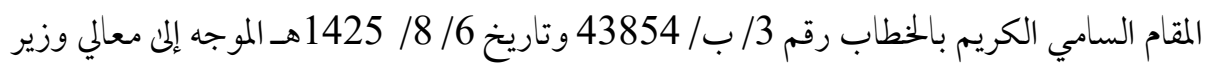


التعليم في المملكة العربية السعودية لتنفيذ مشروع تطوير الرياضيات والعلوم الطبيعية (وزارة التربية

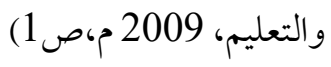

$$
\text { - - ماهداف مشروع تطوير مناهج العلوم: - }
$$

مهدف مشروع تطوير مناهج العلوم والرياضيات في المملكة العربية السعودية وفقاً لما ذكرته وزارة التربية والتعليم (2006: ص 19) الشدوخي ونجوكن شاهين (2007م: ص 441) الما ما يلي: بناء مناهج الرياضيات والعلوم الطبيعية والمواد التعليمية الداعمة لها (الكتب المدرسية الخاصة بالرياضيات والعلوم الطبيعية أدلة المعلمين والمعلمات كراسة النشاط كراسة التجارب العملية الشفافيات الاقراص التعليمية المدججة) بما يضاهي أحدث ما توصلت له الدول المتقدمة في هذا المجال. - مال. الحصول علن أحدث ما توصلت اليه مؤسسات ومراكز البحث العلمي من المعايير و البحوث التقويمية في مجال تطوير الرياضيات والعلوم الطبيعية في مدارس التعليم العام. الاستفادة من نتاج الخبرات العالمية البارزة والمتخصصة في إنتاج المواد التعليمية المساندة وتوظيف التقنية في عمليات تطبيق مناهج الرياضيات والعلوم الطبيعية في مدارس التعليم العام. التطوير المهني للمعلمين والمعلمات والمشرفين والمشرفات وخبراء المناهج في المملكة العربية السعودية من خلال الدعم والتطوير المستمر من بيوت الخبرة العالمية المتخصصة في هذا المجال ومن خلال التدريب علن المعايير العالمية والفلسفية التي بنيت عليها سلاسل الرياضيات والعلوم واساليب التدريس والتقويم والادارة الصفية ودمج التقنية في العلوم.

$$
\text { دمج التقنية وتطبيقاتها في المنهج المدرسي. }
$$

تحسين مستوى تعلم المتعلمين بـا يتفق ومبادئ التعلم النشط والتعلم الذاتي والوصول

للمعرفة وبنائها.

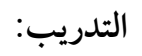

http://dx.doi.org/10.29009/ijres.3.1.7 
يُعد العنصر البشري أهم الموارد وأثمنها علن الإطلاق لا سيّّا إذا كان هذا العنصر مسلحاً

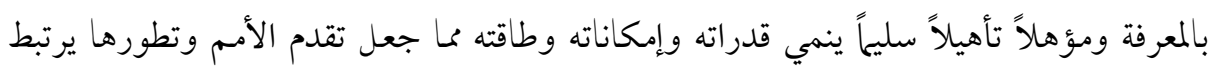

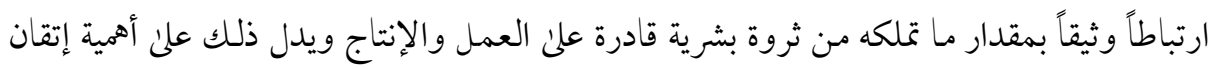

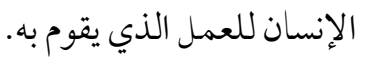

يعرف ربايعة (2003م) الثدريب علن أنه " النشاط الحاص باكتساب وزيادة معرفة ومهارة

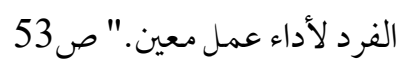

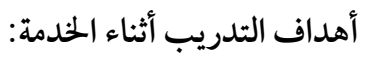

تختلف أهداف التدريب تبعاً لنوع التدريب وطبيعته، والتي علن أساسها يتم تحديد

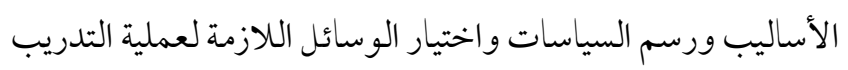

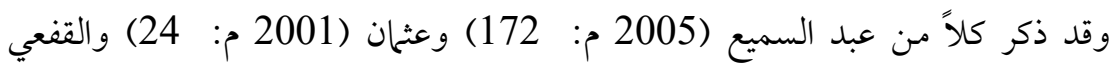

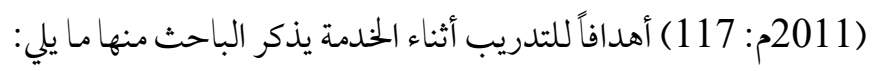
إكساب المثدربين معارف ومهارات جديدة في مجال عملهم. رفع الكفاية الإنتاجية بزيادة الكفاية الفنية للمعلمين. تنمية بعض الاتجاهات الإيجابية نحو العمل والعلاقات الإنسانية بين المتدربين.

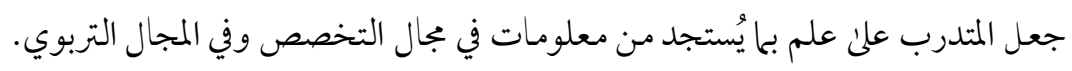

$$
\text { إكساب أساليب التعلم المستمر للمتدربين. }
$$

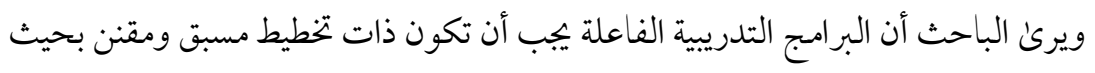

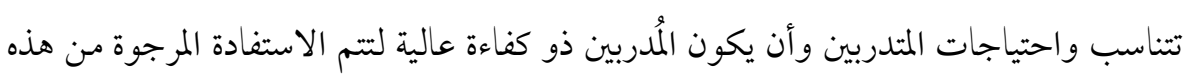
البرامج التدريبية.

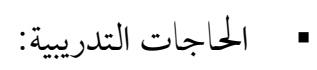


يعد أي عمل معرض للنقص، والحاجة هنا مفهومها وجود فجوة بين ما يمتلكه الشخص، وبين الأداء المرغوب فيه، وهذه الفجوة تظهر نتيجة فقدان الفرد لبعض المهارات والمعارف،

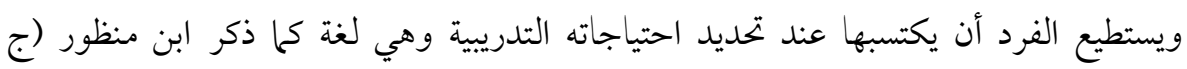
1414،هـ، ) بأنها: "جمع حاجة وهي المأربة، وتحوج الشيء أي احتاج إليه، والحوج هو الطلب"

إن كثيراً من القطاعات يزداد اهتمامها بتدريب كوادرهم لتزداد إنتاجيتهم وذلك وفق برامج خخطط لها فقد ذكرت عفاف الياور (2005 م) " أن تحديد الاحتياجات التدريبية يعد القاعدة الأساسية التي تنطلق منها عملية التخطيط والتصميم للبرامج التدريبية المختلفة، سواء كانت برامج تربوية أو غير تربوية، وسواء كانت برامج خضصصة لقطاع التعليم أم لقطاع الأعمال، فالآلية واحدة ويمكن إتباعها في كل منظطات التدريب لمعرفة الاحتياجات التدريبية التي تساعد في وضع الأهداف تريف

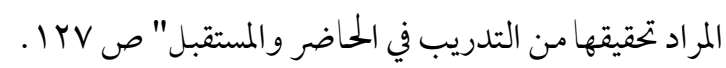
ومما تقدم يمكن استنتاج أن الحاجات التدريبية تتضمن جانبين :

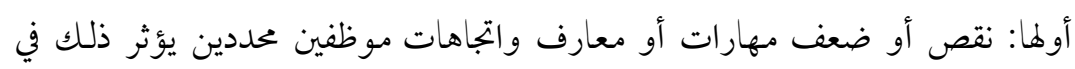
أدائهم وسلوكهم وفي أداء المؤسسة بشكل عام. وثانيها: أنها بجموعة من المهارات والمعارف والاتجاهات المتوقع حاجة موظفين معينين إليها في المستقبل نتيجة لتغيرات وتطورات تكنولوجية، وتنظيمية، أو عملية، أو بسبب ترقيات أو

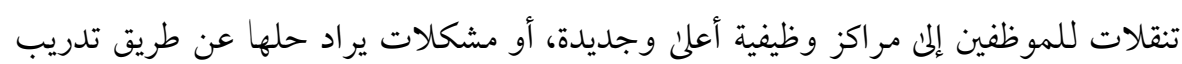

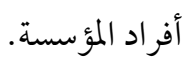
وينطبق هذا الوصف علن معلمي العلوم في المملكة العربية السعودية، فتغير مناهج العلوم أدت إلى إبراز حاجات متنوعة لدى المعلمين منها حاجات معرفية وأخرى حاجات تربوية تدريسية، ويمكن تحديد الحاجات باختلاف أنو اعها بعدة طرق ووسائل. أساليب جمع البيانات لتحديد الاحتياجات التدريبية: 
إن مصادر تحديد الاحتياجات التدريبية تشتمل علن رأي الرئيس المباشر في أداء موظفيه،

والوصف الوظيفي، وتصنيف الوظائف، مما يسهل مقارنة مؤهلات شاغل الوظيفة بمتطلبات

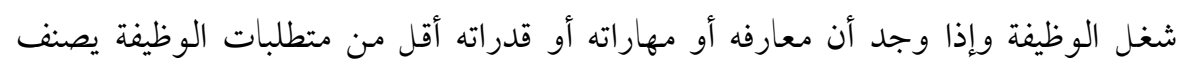
الشخص بأنه يحتاج إلى تدريب .وهناك مصادر أخرىن مثل الملاحظة أثناء تأدية العمل، والتقارير الفنية لمراقبة الأداء ومن أهم المصادر رأي الموظفين من خلال مقابلاتهم الشخصية، وتوصيات المسؤولين عن الاختيار والتعيين ومؤشرات كثرة الشكاوئ والغياب وارتفاع نسبة دوران العمل

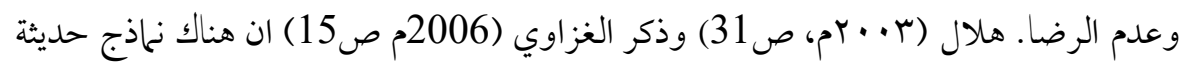
لتحديد الاحتياجات التدريبة منها نموذج روبرت ميجر (Robert Mager) والذي يقوم علن طرح أسئلة بقصد تحليل أداء الأفراد ومن خلال الإجابة علن الأسئلة يتم تحديد الاحتياجات التدريبية .ونموذج دوجان ليرد (Dugan Laird)والذي يقوم علن تحديد الفجوة بين مستويات الأداء والمعايير المحددة وعلني هذا الأساس يتم تحديد الاحتياجات التدريبية. أما وزارة التربية والتعليم (rrع اهـ، ص 77) فقد ذكرت في دليل التدريب التربوي والابتعاث أهم مصادر التعرف علن الاحتياجات التدريبية والتي تتفق مع هلال (2003م) والغزاوي (2006 م) وهي كالتالي:

\section{مهام الوظيفة وواجباتها ومسؤولياتها والمتطلبات الأساسية لشغلها.}

معدلات الأداء المطلوبة للوظائف، وذلك بمقارنتها بأداء العاملون الذين يشغلونها

$$
\text { تقارير الأداء الوظيفي التي تحرر من قبل المدير المباشر أو المشرف التربوي. }
$$

المستجدات والتطورات التي طرأت علن الوظيفة تعد مؤشرًا للاحتياجات التدريبية لمواكبة

هذا التطور.

أهداف المؤسسة التربوية حيث تعطينا مؤشراً عاماً علن الاحتياجات التدريبة اللازمة

$$
\text { للموظفين لتحقيق هذه الأهداف. }
$$

العاملون في الحقل التربوي هم أنفسهم أقدر الناس علن تحديد احتياجاتهم التدريبية. 
الدراسات التي طبقت علن العاملين في حقل التربية والتعليم لغرض تقدير احتياجاتهم التدريبية تعطينا مؤشراً عاماً على احتياجاتهم التدريبية.

$$
\text { • آراء الرؤساء المباشرين. }
$$

لما كان الهدف الأسمى للتعليم هو زيادة الفاعلية العقلية للطلبة، ورفع مستوى كفايتهم الاجتماعية، فإن المعلم يجب أن يكون لدية قدرة عقلية تمكنه من مساعدة طلابه علن النمو العقلي، والسبيل إلى ذلك هو أن يتمتع المعلم بغزارة المادة العلمية، وأن يكون مستوعباً لمادة تخصصه أفضل

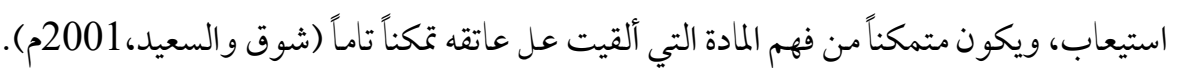

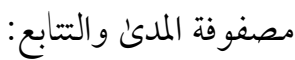

تعتبر مصفوفة المدىن والتتابع ركن من الأركان الأساسية في تنظيم محتوى منهج مادة العلوم إذ تكشف من أين أتى كل موضوع وإلى أين سينتهي، لذا، فإن تنظيم محتوى الكتاب المدرسي يُعتبر من المتطلبات الأساسية في تطوير المناهج، وتحتاج عملية التنظيم من مطوري المناهج إدراك العلاقات بين أفكار المحتوىن ومفاهيمه الأساسية لبناء محتوى ذي معنى، إذ ليس

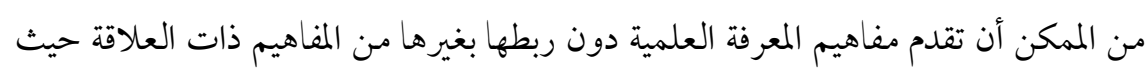
إنه من المتفق عليه أن إحدئ غايات تقديم المعرفة المنظمة في كتاب الطالب هو تمكينه من إدراك العلاقات التي تربط بين مكونات المعرفة في كل مجال من مجالاتها، ولا يمكن أن يتم ذلك إلا بواسطة استراتيجية تبرز روابط مكونات المحتون وتكامله.

$$
\text { اساليب تنظيم المحتوى: - n }
$$

التنظيم المنطقي: هو ترتيب الموضوعات والخبرات ترتيبًا منطقيًا، أي إيجاد علاقات بين المراكز التنظيمية. حيث يُبنى هذا التنظيم علن تشكيل خرائط مفاهيمية لمفاهيم يتم تناوها في صف من الصفوف، وتدفقها عبر الصفوف المتلاحقة. والتنظيم المنطقي هو الأكثر

\section{http://dx.doi.org/10.29009/ijres.3.1.7}




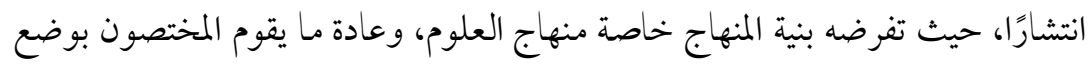

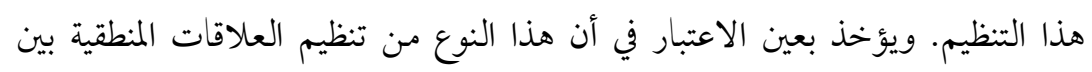

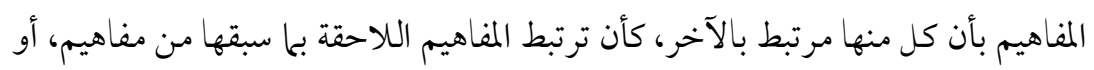

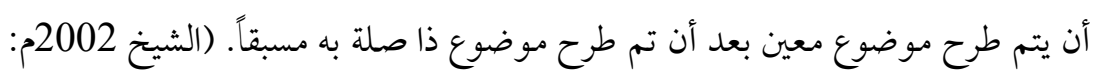
ص 99) التنظيم النفسي السيكولوجي: والمرجعية في هذا التنظيم هو الطالب، بحيث يتم تنظيم

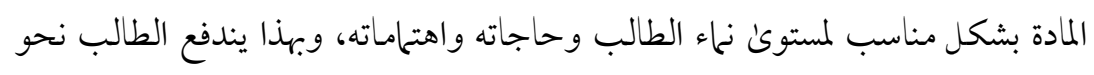

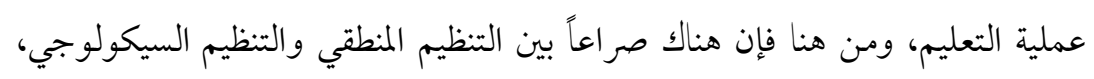

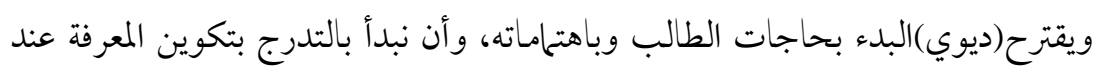

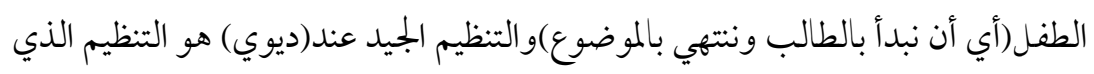

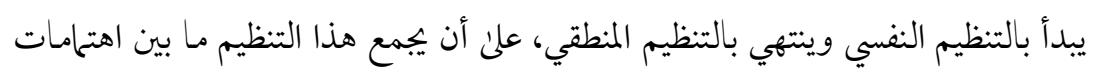

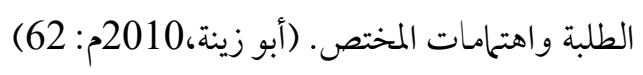
الدراسات السابقة: أورد الأدب التربوي عدداً من الدراسات المرتبطة بهذه الدراسة، وقد قام الباحث بتقسيمها علن

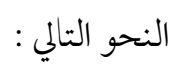
الدراسات التي تناولت الحاجات التدريبية: • أعد القرشي (1431 هـ) دراسة هدفت إلى تقويم برنامج تدريب المعلمين علن سلسلة

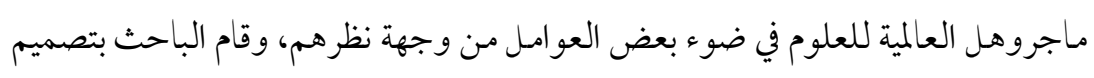

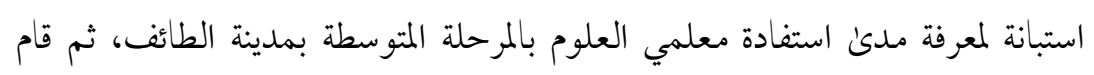

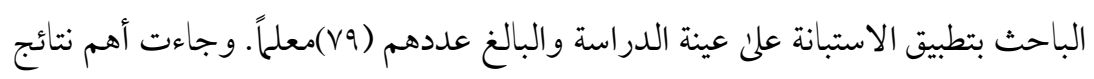

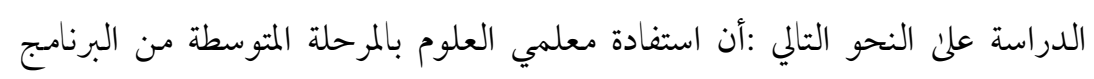

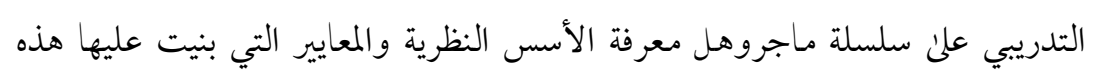


السلسلة - التعرف على طرائق التدريس المستخدمة في هذه السلسلة - معرفة أساليب التقويم - دمج مهارات اللغة والرياضيات في تدريس العلوم - اكتساب مهارات الإدارة الصفية الفاعلة في تدريس العلوم - توظيف المواد التعليمية المساندة في التدريس) كانت جميعها بدرجة متوسطة، وأن درجة المشكلات التي تواجه معلمي العلوم في المرحلة المتوسطة بمدينة الطائف للاستفادة من برنامج تدريب المعلمين على سلسلة ماجروهل العالمية للعلوم كانت بدرجة عالية. وفي دراسة قام بها جاداله (2010م) هدفت المن تحديد الاحتياجات التدريبية لدى معلمي المرحلة الأساسية بمحافظة غزة بمحاور الدراسة وهي: اختيار طرائق التدريس المناسبة وبناء الخطط العلاجية والتعرف على محتوىن مادة التخصص وامتلاك مهارات طرح الاسئلة. ويلغ عدد افراد عينة الدراسة (400) معلماً ومعلمة. واعتمدت هذه الدراسة المنهج الوصفي التحليلي واظهرت نتائج هذه الدراسة ترتيباً للاحتياجات التدريبية حسب الاهمية من وجهة نظر عينة الدراسة ومنها: بناء الخطط العلاجية اختيار طرائق التدريس المناسبة امتلاكك مهارات طرح الاسئلة التعرف علئ محتوى مادة التخصص. ثانياً: دراسات تناولت مناهج العلوم المطورة: أجرى عسيلان (1432هـ) دراسة هدفت لمعرفة مدن تحقيق كتاب العلوم المطور للصف الأول المتوسط لمعايير الجودة الشاملة في جوانبه الأساسية: إخراج الكتاب، الأهداف، المحتوى العلمي، أساليب التقويم بالمملكة العربية السعودية. ولتحقيق هذا الهدف قام الباحث ببناء قائمة بمعايير الجودة الشاملة اللازمة توفرها في كتاب العلوم المطور ثم قام بتحليل إخراج الكتاب، وتحليل أهداف كتاب العلوم المطور، وتحليل محتوىن كتاب العلوم المطور، وتحليل أساليب التقويم، وتوصلت دراسته إلى عدة نتائج من أهمها :حصل مجال

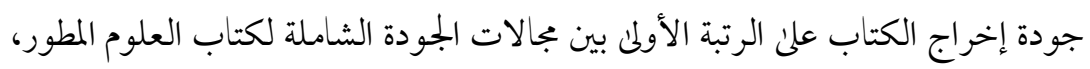
يليه بجال جودة أساليب التقويم، ثم بجال جودة الأهداف، وأخيراً بجال جودة المحتوني 
العلمي، يعد معيار تنمية المهارات العلمية أكثر معايير الجودة تحقيقًا، وحل معيار الارتباط

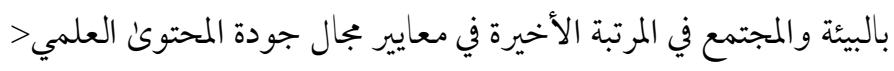

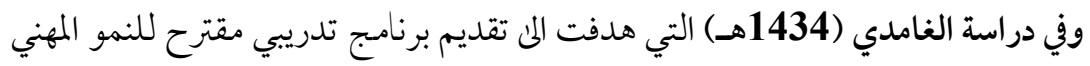

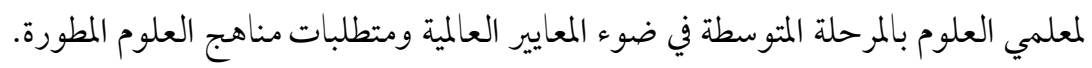

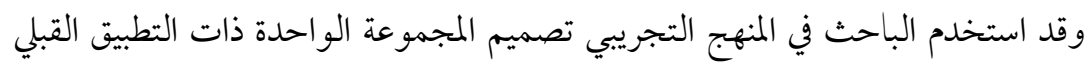

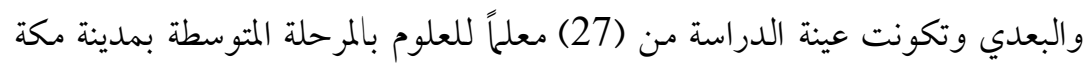
المكرمة وجاءت أهم نتائج الدراسة علن النحو التالي :

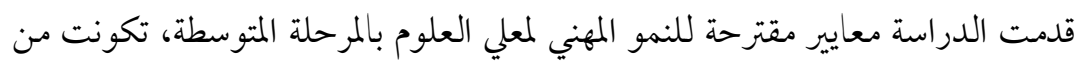
تسعة معايير أساسية تحتوي علن ( ( ) ) مؤشراً فرعياً. قدمت الدراسة متطلبات مناهج العلوم المطورة، وتكونت من ستة متطلبات أسرات أساسية تحتوي علن (OV) عبارة فرعية. قدمت الدراسة برنابجاً تدريبياً مقترحاً للنمو المهني لمعلمي العلوم بالمرحلة المتوسطة، في

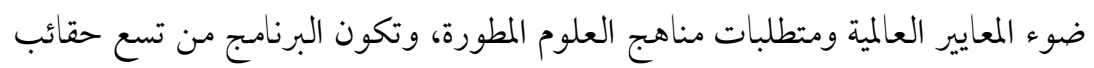

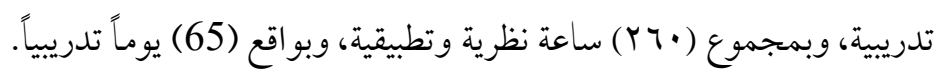

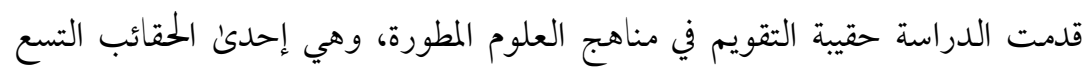

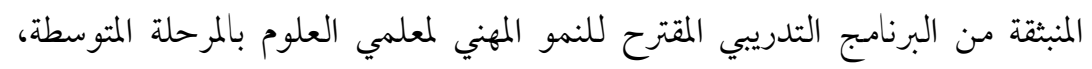
وبواقع (16) ساعة تدريبية علن مدار أربعة أيام.

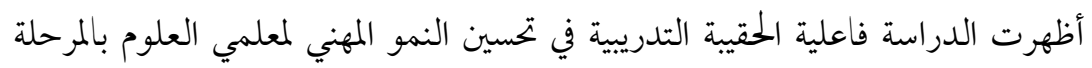

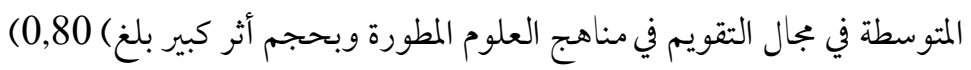

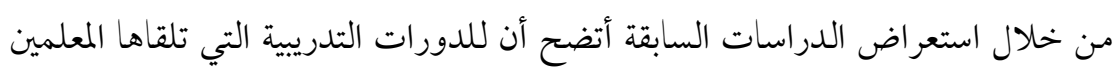

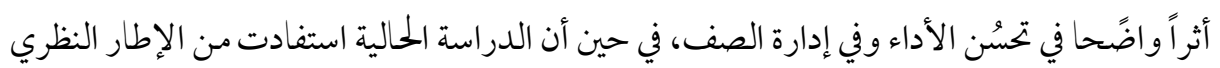

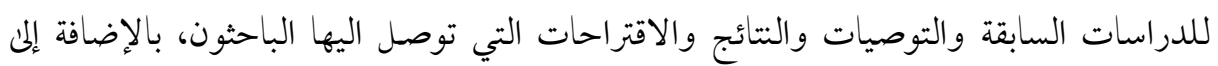


الاطلاع علن الكتب والمراجع العربية والأجنبية التي تم الرجوع اليها أثناء كتابة الدراسات، ومعرفة

$$
\text { الأساليب الإحصائية التي تم استخدامها. }
$$

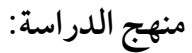

بناءً علن مشكلة الدراسة وأهدافها وتساؤلاتها، فإن المنهج المناسب لهذه الدراسة هو المنهج

$$
\begin{aligned}
& \text { الوصفي فهو منهج لدراسة الواقع ووصفه وصفاً دقيقًا. } \\
& \text { أداة الدراسة وخطوات بنائها: }
\end{aligned}
$$

هدفت الدراسة إلى تحديد الحاجات التدريبية المعرفية لمعلمي العلوم بالمرحلة المتوسطة في

ضوء مصفوفة المدىن والتتابع لمناهج العلوم المطورة. والتعرف علن تأثير بعض المتغيرات وهي طبيعة

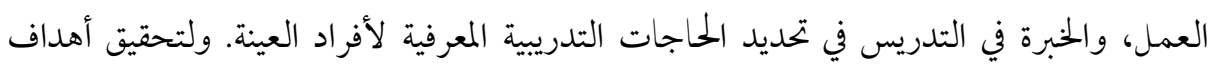
الدراسة تم اختيار الاستبانة كأداة لجممع المعلومات من بجتمع الدراسة. النتائج

يتم استعراض التتائج التي تم التوصل إليها من خلال تحليل استجابات عينة الدراسة

باستخدام برنامج الحزم الإحصائية للعلوم الاجتماعية Statistical Package for Social Sciences

ومن ثم تحديد قيمة المتوسط الحسابي للاستجابة وفقاً لمقياس ليكارت Likertالخحاسي من

خلال حساب المدئ بين الدرجات وذلك باستخدام المعادلة التالية:

\section{$0.8=\underline{1-5}=\underline{1-5}$}

\section{$5 \quad$ الدرجة العليا}

ومناقشة تلك النتائج في ضوء الإطار النظري للدراسة والدراسات السابقة وتبيان من يتفق منها مع هذه النتائج وما يختلف. وفيما يلي استعر اض لتلك النتائج وفقاً لأسئلتها.

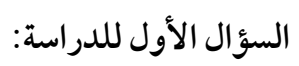


ما الحاجات التدريبة المعرفية لمعلمي العلوم في ضوء مصفوفة المدى والتتابع لمناهج العلوم

المطورة؟

للإجابة على السؤال الأول فقد تم حساب المتوسطات الحسابية والانحرافات المعيارية لكل

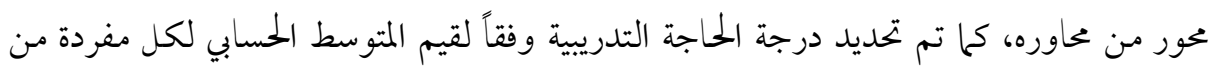
المفردات الوسط الحسابي والانحراف المعياري ودرجة الحاجة للتدريب لكل محور من محاور مصفوفة

المدئ والتتابع في منهج العلوم المطور بالمرحلة المتوسطة

\begin{tabular}{|c|c|c|c|c|c|}
\hline درجة الحاجة & الانحراف & المسابي & المحور & الترتيب حسب درجة & ترتيب المحور في \\
\hline متوسطة & 0,748 & 3,37 & والعلم و التقنية & الاول & الخامس \\
\hline متوسطة & 0,766 & 3,34 & علم الأرض & الثاني & الثانية \\
\hline متوسطة & 0,752 & 3,34 & العلوم الطبيعية & الثالث & الثالث \\
\hline متوسطة & 0,807 & 3,30 & الاستقصاء العلمي & الرابع & 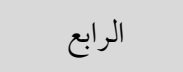 \\
\hline متوسطة & 0,726 & 3,19 & علم الحياة & الخامس & الأول \\
\hline
\end{tabular}

يوضح الجدول السابق من وجهة نظر عينة الدراسة ان الحاجة إلى تدريب معلمي العلوم

بالمرحلة المتوسطة علن معارف ومحتويات المحور الخامس: العلم والتقنية والمجتمع تأتي في المرتبة الأولم، حيث بلغ المتوسط الحسابي (3.37) بانحراف معياري (0.748). وتساون محوري علم الأرض والعلوم الطبيعية في المرتبة الثانية بمتوسط حسابي (3.34) وانحراف معياري (0.766) و (0.752) علن التوالي. أما المحور الرابع: الاستقصاء العلمي فقد سبق المحور الأول علم الحياة، الذي احتل المرتبة الأخيرة، بفارق في المتوسط الحسابي مقداره (0.11)؛ وتشير قيمة الانحراف المعياري 
لكل محور إلى أن استجابات عينة الدراسة على المحور الأول أكثر تجانساً منها علن المحور الرابع. ويتفق الباحث مع رأي عينة الدراسة علن أن محور العلم والتقنية والمجتمع أكثر حاجة إلى تدريب معلمي

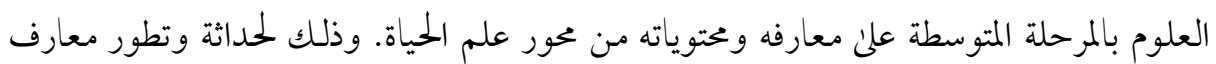
ومحتويات هذا المحور ولورود بعض المعارف في محور علم الحياة ضمن المناهج القديمة راء افراد العينة ان درجة الحاجة الما التدريب في هذا المحور متوسطة ويتفق الباحث مع هذا الرأي باستثناء بعض المعارف التي حصلت علئ درجة كبيرة من الحاجة للتدريب في هذا المحور. نخلص من النتائج أعلاه أن معلمي المرحلة المتوسطة بحاجة كبيرة للتدريب على كثير من المعارف والمحتويات في مناهج العلوم المطورة في ضوء مصفوفة المدئ والتتابع، وبدرجة متوسطة علن جميع المعارف والمحتويات. ويرجع الباحث تلك الحاجة بهذه الدرجة، إلى تغير مناهج العلوم في المملكة العربية السعودية التي أدت إلى إبراز حاجات تدريبية متنوعة لدىن المعلمين. وكذلك نتيجة للتغيرات والتطورات العلمية والتقنية الحديثة في مجال مـادة العلوم، والتي أدت إلى ظهور معارف ومفردات حديثة ييب التطرق لها في مناهج العلوم بالمرحلة المتوسطة. وتتفق هذه النتائج مع دراسة كل من رفاع (1993م) حيث جاء محور المعارف والمهارات في المرتبة الاولن من حيث الاحتياجات للتدريب، ودارسة منيرة الفهيد (1419هـ) حيث اكدت نتائج دراستها على ان هناك احتياجات تدريبية كثيرة في مجالات التخطيط وتنفيذ الدروس وفي المجال المعرفي وطرائق التدريس، ودراسة أبو الحمايل (1419هـ) التي ذكر في نتائجها وجود كثير من الموضوعات التي يجتاج المعلمين المى التدريب عليها كالمعارف المتعلقة بمحتوى المنهج وبالوسائل التعليمية، ودراسة ساله (2002م) التي بينت نتائجها وجود احتياجات تدريبية لمعلمي العلوم في بجال العلوم البيئية. وللإجابة على السؤال الثاني، والذي نصه: هل تختلف الحاجات التدريبية المعرفية لمعلمي العلوم في ضوء مصفوفة المدى والتتابع لمناهج

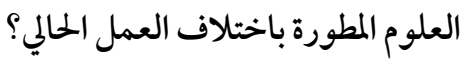


تم إجراء اختبار (ت) للعينات المستقلة، حيث أن العمل الحلالي لأفراد عينة الدراسة قد قسم إلى فئتين (معلم، مشرف تربوي). والجدول التالي يوضح نتائج الاختبار. نتيجة اختبار (ت) للعينات المستقلة لمعرفة الفروق في متوسطات تقدير أفراد عينة الدراسة لدرجة حاجة معلمي العلوم للتدريب في ضوء مصفوفة المدىن والتتابع لمناهج العلوم المطورة في جميع المحاور والتي تعزئ إلى متغير العمل الحلالي لأفراد العينة

\begin{tabular}{|c|c|c|c|c|c|c|c|}
\hline الإحصائية & درجة الحرية & قلميمة (ت) & الالنحراف & المتوسط & | العدد & العمل العلي & المحور \\
\hline 0.005 & 148 & $2,883-$ & 0,694 & 3,15 & $\begin{array}{r}140 \\
10\end{array}$ & مشرف & علم الحياة \\
\hline 0.001 & 148 & $3,864-$ & 0,617 & 3,27 & $\begin{array}{r}140 \\
10\end{array}$ & مشرف & علم الارض \\
\hline 0.022 & 148 & $2,322-$ & 0,705 & 3,30 & 140 & مشرف & العلوم الطبيعية \\
\hline 0.003 & 148 & $3,675-$ & 0,760 & 3,24 & 140 & معلم & الاستقصاء العلمي \\
\hline
\end{tabular}




\begin{tabular}{|c|c|c|c|c|c|c|c|}
\hline الإحصائية & درجة الحرية & قالمحسوبة (ت) & الالنحراف & الملتوسط & |العدد | & العمل العلالي & المحور \\
\hline & & & 0,971 & 4,17 & 10 & مشرف & \\
\hline \multirow[b]{2}{*}{0.004} & \multirow[b]{2}{*}{148} & \multirow[b]{2}{*}{$2,940-$} & 0,715 & 3,33 & 140 & معلم & \multirow{2}{*}{ والملم والتقنية } \\
\hline & & & 0,930 & 4,03 & 10 & تربوف & \\
\hline
\end{tabular}

يوضح الجدول السابق أنه توجد فروق ذات دلالة إحصائية عند مستون دلالة إحصائية ( م0.05) ودرجة حرية (148) في متوسطات تقدير أفراد العينة لدرجة حاجة معلمي العلوم بالمرحلة المتوسطة للتدريب علن معارف ومحتويات جميع محاور الاداة في ضوء مصفوفة المدئ والتتابع لمناهج العلوم المطورة ولصالح المشرفيين التربويين. حيث نجد أن متوسط تقدير المشرفيين التربويين لحاجة معلمي العلوم للتدريب أعلن من متوسط تقدير المعلمين، وتشير هذه النتيجة أن هذا الاختلاف في متوسط تقدير درجة الحاجة يعزى للعمل الحالي لأفراد العينة. وتتفق هذه النتيجة مع نتيجة ساله (2002م) حيث اظهرت نتائج دراسته وجود فروق بين تقديرات المشرفين التربويين والمعلمين لأهمية

$$
\text { الاحتياجات التدريبية لصالح المشرفين التربويين. }
$$

ويفسر الباحث تلك التيجة باطلاع المشرفين التربويين علن المستوكن المعرفي في العلوم لعدد كبير من المعلمين بحكم عملهم الاشرافي، والذي يتطلب منهم زيارة المدارس وحضور الحصص الصفية، والمشاركة في تدريب المعلمين، مما جعلهم يدركون حقيقة المعرفة العلمية لمعلمي العلوم، وهذا من شأنه جعل حكم المشرفين التربويين وتقديرهم للحاجات التدريبية المعرفية أكثر وأعلن من تقدير المعلمين لأنفسهم. وللإجابة على السؤال الثالث، والذي نصه: هل تختلف الحاجات التدريبية المعرفية لمعلمي العلوم في ضوء مصفوفة المدى والتتابع لمناهج العلوم المطورة باختلاف الخبرة في التدريس؟ 
تم إجراء اختبار (ت) للعينات المستقلة، حيث أن الخبرة التدريسية لأفراد عينة الدراسة من

$$
\text { معلمين ومشرفين قد قسمت إلى فئتين (أقل من ثمان سنو ات، ثمانية سنو ات فأكثر ). }
$$

نتيجة اختبار (ت) للعينات المستقلة لمعرفة الفروق في متوسطات تقدير أفراد عينة الدراسة لدرجة حاجة معلمي العلوم بالمرحلة المتوسطة للتدريب في ضوء مصفوفة المدئ والتتابع لمناهج العلوم المطورة، في جميع المحاور والتي تعزئ إلى متغير الخبرة التدريسية لأفراد العينة.

\begin{tabular}{|c|c|c|c|c|c|c|c|}
\hline الإحصائية & درجة & قلمحة (ت) & الانحر اف المياري & المسابي & العدد & سنوات الخخبرة & المحور \\
\hline \multirow[t]{2}{*}{0.903} & \multirow[t]{2}{*}{148} & \multirow[t]{2}{*}{0,122} & 0,645 & 3,21 & 20 & سنو سن من & \multirow[t]{2}{*}{ علم الحياة } \\
\hline & & & 0,739 & 3,19 & 130 & ثمان سنوات فأكثر & \\
\hline \multirow[t]{2}{*}{0.947} & \multirow[t]{2}{*}{148} & \multirow[t]{2}{*}{ 0,067- } & 0,474 & $3, \mathbf{3 3}$ & 20 & سنو أقل من & \multirow{2}{*}{ علم الارض } \\
\hline & & & 0,803 & 3,34 & 130 & ثمان سنوات فأكثر & \\
\hline \multirow[t]{2}{*}{0.663} & \multirow[t]{2}{*}{148} & \multirow[t]{2}{*}{0,436} & 0,655 & 3,41 & 20 & سنوات من ثنان & \multirow[t]{2}{*}{ العلوم الطبيعية } \\
\hline & & & 0,768 & 3,33 & 130 & ثمان سنوات فأكثر & \\
\hline \multirow[t]{2}{*}{0.976} & \multirow[t]{2}{*}{148} & \multirow[t]{2}{*}{ 0,030- } & $\mathbf{0 , 6 5 0}$ & 3,29 & 20 & سنوات من ثنان & \multirow{2}{*}{ الاستقصاء } \\
\hline & & & $\mathbf{0 , 8 3 0}$ & $\mathbf{3 , 3 0}$ & 130 & ثمان سنوات فأكثر & \\
\hline \multirow[t]{2}{*}{0.901} & \multirow[t]{2}{*}{148} & \multirow[t]{2}{*}{$\mathbf{0 , 1 2 5}$} & $\mathbf{0 , 5 9 9}$ & 3,39 & 20 & سنوات من ثمان & \multirow{2}{*}{ العلم والتقنية } \\
\hline & & & $\mathbf{0 , 7 7 0}$ & $\mathbf{3 , 3 7}$ & 130 & ثمان سنوات فأكثر & \\
\hline
\end{tabular}




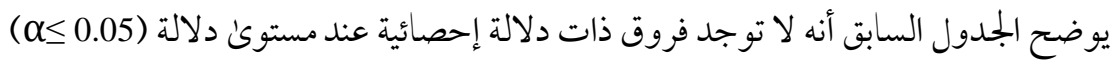
ودرجة حرية (148) تعزئ لمتغير الخبرة التدريسية في متوسطات تقدير أفراد العينة لدرجة حاجة معلمي العلوم في ضوء مصفوفة المدىن والتتابع لمناهج العلوم المطورة في جميع المحاور. ويرجع الباحث هذا الاتفاق بين الفئتين في جميع المحاور إلى توافق وجهات نظر مجتمع الدراسة سواء المعلمين الذين خبرتهم في التدريس أو الاشراف التربوي أقل من ثمان سنوات أو ثمان سنوات فأكثر، فهم ربها يرون أن الدورات التدريبية مهمة ويتطلب منهم المشاركة فيها، بعيداً عن كونه معلم خبرته التدريسية قصيرة أو خبرته طويلة. وتتفق نتائج هذه الدراسة مع دراسة القرني (2012 م) حيث ذكرت انه لا يوجد فروق ذات دلالة احصائية تعزي لمتغير عدد سنوات الخبرة في التدريس.

\section{توصلت الدراسة إلى النتائج التالية:}

- هنالك حاجة إلى تدريب معلمي العلوم بالمرحلة المتوسطة في ضوء مصفوفة المدىن والتتابع لمناهج العلوم المطورة في بعض المعارف والمحتويات بدرجة كبيرة، وفي البعض الآخر

$$
\text { بدرجة متوسطة. }
$$

- إن الحاجة إلى تدريب معلمي العلوم بالمرحلة المتوسطة على معارف ومحتويات محور العلم و التقنية والمجتمع تأتي في المرتبة الأولن، يليها محوري علم الأرض والعلوم الطبيعية في المرتبة

$$
\text { الثانية ثم محور الاستقصاء العلمي وأخيراً محور علم الحياة. }
$$

- توجد فروق ذات دلالة إحصائية عند مستوى دلالة (148) تقدير المعلمين والمشرفين التربويين لدرجة حاجة معلمي العلوم بالمرحلة المتوسطة للتدريب علن معارف ومحتويات مناهج العلوم المطورة في ضوء مصفوفة المدئ والتتابع لصالح المشرفيين التربويين. 
- لا توجد فروق ذات دلالة إحصائية عند مستوى دلالة (148) تعزىن لمتغير الخبرة التدريسية لمعلمي ومشرفي العلوم في تقدير درجة حاجة معلمي العلوم للتدريب علن معارف ومحتويات مناهج العلوم المطورة في ضوء مصفوفة المدئ والتتابع.

في ضوء النتائج التي توصلت إليها الدراسة يوصي الباحث بها يلي:

- - إعادة النظر في برامج تدريب معلمي العلوم بالمرحلة المتوسطة لتغطية الجوانب المعرفية

$$
\text { لمناهج العلوم المطورة في ضوء مصفوفة المدىئ والتتابع. }
$$

- الاهتحام بالمعارف والمحتويات الحديثة لمناهج العلوم المطورة والتركيز على محور العلم والتقنية والمجتمع ومحور العلوم الطبيعية وعلم الأرض وإدراجها ضمن برنامج تدريب

$$
\text { معلمي العلوم بالمرحلة المتوسطة. }
$$

- حيث أن منهج العلوم من المناهج التي يطرأ عليها التغيرات والتطورات في ظل التقدم العلمي والتكنولوجي، عليه نوصي القائمين على شؤون التدريب بإعادة تقييم برامج تدريب معلمي العلوم بالمرحلة المتوسطة دورياً لمعرفة الحاجات التدريبية للمعلمين بالمرحلة. 
من خلال استعراض الدراسات السابقة والإطار النظري للدراسة، وفي ظل النتائج التي توصلت إليها الدراسة، يقترح الباحث أن يتم اجراء بعض الدراسات في المواضيع التالية:

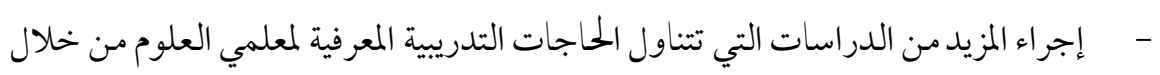
تطبيق أدوات بحثية أخرى مثل الاختبارات. - - إجراء مزيد من البحوث والدراسات المماثلة لمراحل أخرىن. 
1. أبو زينة، فريد. (2010م) .تطوير مناهج الرياضيات المدرسية وتعلمها ط (1): دار وائل

$$
\text { للنشر والتوزيع، عمان الاردن. }
$$$$
\text { 2. ابن منظور، جمال الدين. (1414هـ). لسان العرب. ط2، بيروت: دار صادرن. }
$$

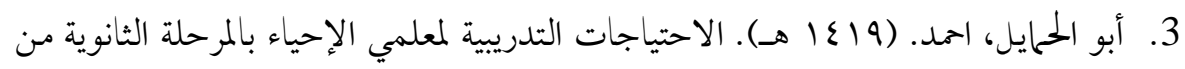

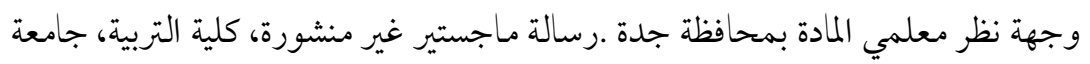

$$
\text { أم القرىن، مكة المكرمة. }
$$

4. الرومي، نايف . (2009 م )تعميم مشروع تطوير الرياضيات والعلوم .جريدة الرياض، عدد 14885

5. الشيخ، عمر .(2002م) .المعلم الذي نريد للقرن الحادي والعشرين في المدرسة الأردنية وتحديات القرن الو احد و العشرين. مؤسسة عبد الحميد شومان، عمان الاردن.

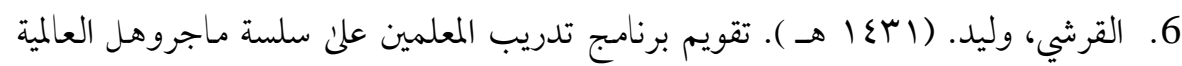

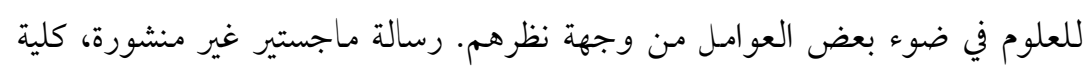
التربية، جامعة أم القرىن، مكة المكرمة.

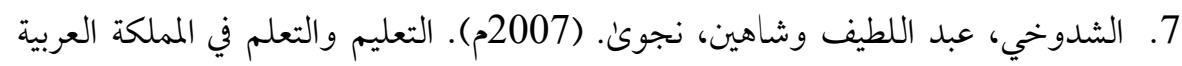

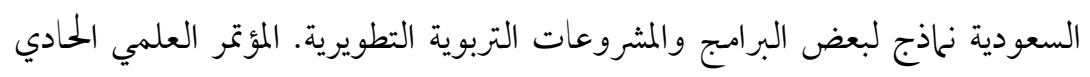

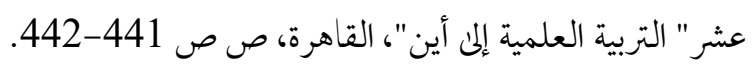
8. الشهري، علي. (1422هـ). تحديد الاحتياجات التدريبية لمعلمي العلوم من تقنيات التعليم التهاتيه بالمرحلة المتوسطة كما يراها المشرفون التربويون ومديرو المدارس والمعلمون بمحافظة

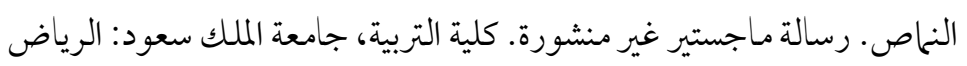

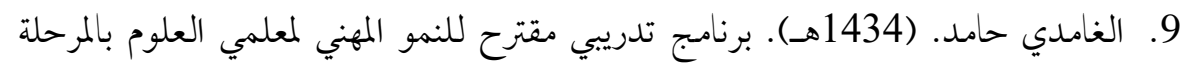

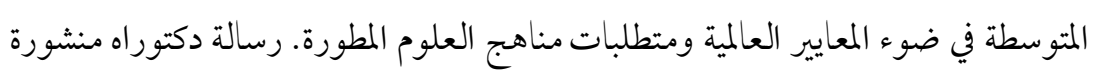
كلية التربية جامعة أم القرى مكة المكرمة. 
10. العسبلي، منصور .2010م) .دراسة تحليلية لمحتوى برامج تدريب المعلمين عن بعد القائمة

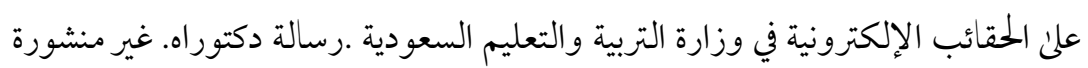
الجامعة الأردنية، عمان الاردن.

11.القفعي خميس. (2011م) الاحتياجات التدريبية للمشرف التربوي في مجتمع المعرفة. رسالة ماجستير غير منشورة كلية التربية جامعة أم القرى مكة المكرمة. 12.الفهيد، منيرة. (1419هـ). الحاجات التدريبية لمعلمات العلوم في المرحلة المتوسطة بمدينة الرياض. رسالة ماجستير غير منشورة، كلية التربية، جامعة الملك سعود: الرياض. 13.الياور، عفاف. (2005م). التدريب التربوي في ضوء التحولات المعاصرة ـ القاهرة: دار الفكر العربي.

14.العزاوي، نجم. (2006م). التدريب الإداري. الطبعة الأولن: دار اليازوري العلمية للنشر

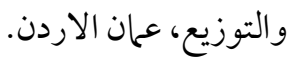

15.جاداله فوزي. (2010 م) الاحتياجات التدريبية لدىن معلمي المرحلة الاساسية في المدارس الحكومية بمحافظة غزة. رسالة ماجستير غير منشورة جامعة الأزهر غزة فلسطين

16.عبدالسلام مصطفىل. (2007م). اساسيات التدريس والتطوير المهني للمعلم. الطبعة الثانية الاسكندرية مكتبة الجحامعة الجمديدة.

17. عبدالسميع مصطفى و حو اله سهير. (2005م). إعداد المعلم تنميته وتدريبه: دار الفكر عمان الاردن.

18.عثمان، محمد. (2001م). تدريب المعلمين أثناء الخدمة. ط 1: مكتبة الخبتي الثقافية المملكة العربية السعودية. 19.عسيلان، بندر. (1432هـ). تقويم كتاب العلوم المطور للصف الأول المتوسط في ضوء معايير الجودة الشاملة، رسالة ماجستير غير منشورة، كلية التربية، جامعة أم القرىن. 
20. ساله، صلاح الدين. (2002م). الاحتياجات التدريبية لمعلمي العلوم البيئية بالمرحلة الثانوية

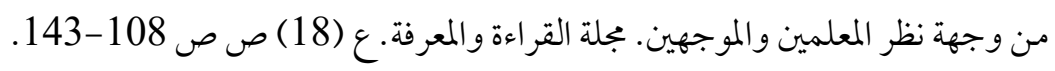

21.شوق، محمود السعيد، محمد .(2001م ). معلم القرن الحادي والعشرين (اختياره- إعداده -

$$
\begin{aligned}
& \text { تنميته) في ضوء التوجهات الإسلامية: دار الفكر العربي، القاهرة. } \\
& \text { 22. ربايعة علي. (2003م). إدارة الموارد البشرية: دار صفاء علان الاردن. }
\end{aligned}
$$

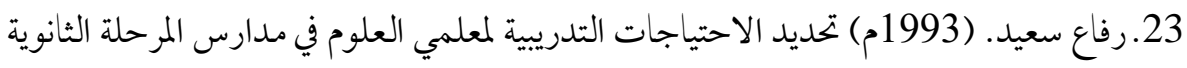

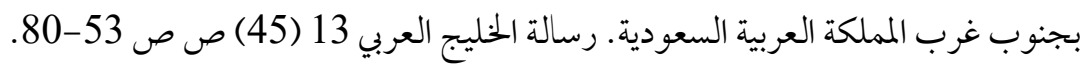

24.وزارة التربية والتعليم. (2009 م). مشروع تطوير الرياضيات والعلوم الطبيعية. الرياض.

$$
\text { العبيكان للأبحاث والتطوير. }
$$

25.وزارة التربية والتعليم. (2006 م) مشروع تطوير مناهج العلوم والرياضيات في المملكة العربية السعودية. أمانة مشروع تطوير مناهج العلوم والرياضيات مطابع ركن الطباعة. 26. هلال، محمد. (2003م). دراسة الاحتياجات والتخطيط للتدريب .مصر الجديدة: مركز

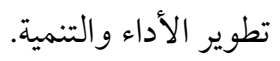




\section{References:}

- Abdel-Samia, Mostafa and Hawala, Suhair. (2005). Preparation of teacher development and training: Dar Al-Fikr, Amman, Jordan.

- Abdul Salam, Mustafa. (2007). The basics of teaching and professional development of the teacher. Second Edition, Alexandria, New University Library.

- Abu Hamayel, Ahmed. (1419 h). Training needs of secondary education teachers from the point of view of material teachers in Jeddah. Master Thesis unpublished, Faculty of Education, Umm Al-Qura University, Makkah.

- Abu Zeina, Farid. (2010). Curriculum Development and Learning (1): Dar Wael Publishing and Distribution, Amman, Jordan.

- AL- Fahd, Munira (1419 h). Training Needs for Science Teachers in the Intermediate Stage in Riyadh City. Master 's thesis unpublished, College of Education, King Saud University: Riyadh.

- AL-Asbali, Mansour. (2010). (Analytical study of the content of distance learning programs based on e-portfolios in the Ministry of Education, Saudi Arabia, $\mathrm{PhD}$ thesis, unpublished, University of Jordan, Amman, Jordan.

- Al-Azzawi, Najm (2006). Management training. First edition: Dar Al Yazuri Scientific Publishing and Distribution, Amman, Jordan.

- $\quad$ Al-Ghamdi, Hamid (1434 h). proposed training program for the professional growth of science teachers in the intermediate stage in light of international standards and the requirements of developed science curricula. $\mathrm{PhD}$ thesis published, Faculty of Education, Umm Al-Qura University, Makkah.

- $\quad$ AL-Qafai, Khamis. (2011) training needs of the educational supervisor in the knowledge society. Master Thesis unpublished, Faculty of Education, Umm Al-Qura University, Makkah.

- $\quad$ Al-Qurshi, Waleed.(1431 h). Evaluation of the Teacher Training Program on the Magrohell International Series of Sciences in light of some factors from 
their point of view Unpublished Master Thesis, Faculty of Education, Umm Al-Qura University, Makkah Al-Mukarramah.

- Al-Roumi, Naif.(2009)the circulation of the project to develop mathematics and science, Riyadh newspaper, number 14885

- Al-Yawar, Afaf (2005). Educational training in the light of contemporary transformations. Cairo: Arab Thought House.

- Asilan, Bandar. (1432 h). Evaluation of the science book developed for the first grade in the light of the overall quality standards, unpublished master thesis, Faculty of Education, Umm Al Qura University.

- Colman, K. (2003). Human Development. CSULB Catalog. University of Florida. Florida. USA.

- Hilal, Mohamed. (2003). Study needs and planning for training. Heliopolis: Center for Development and Performance Development.

- Ibn Manzoor, Jamal al-Din (1414 h). Arabes Tong. I 2, Beirut: Dar Sader.

- Jadallah, Fawzi. (2010) training needs of primary school teachers in public schools in Gaza Governorate. Unpublished MA thesis, Al-Azhar University, Gaza, Palestine

- Osman, Mohamed. (2001). In-service teacher training. 1: Al-Khobti Cultural Library, Kingdom of Saudi Arabia.

- Rabaya, Ali (2003). Human Resource Management: Dar Safa, Amman, Jordan.

- Rafea, Said (1993). Identifying the training needs of science teachers in secondary schools in South West Saudi Arabia. The Message of the Arab Gulf, 13 (45), pp. 53-80.

- Salem, Salahuddin. (2002). The training needs of environmental science teachers in the secondary stage from the point of view of teachers and mentors. Reading and knowledge. (18) pp. 108-143.

- $\quad$ Shadoohi, Abdullatif and Shaheen, Najwa (2007). Education and learning in Saudi Arabia Models for some educational programs and educational 
projects. Eleventh Scientific Conference "Scientific Education to Where", Cairo, pp. 441-442.

- $\quad$ Shahry, Ali (1422 h). Identifying the training needs of science teachers from the educational techniques in the intermediate stage as seen by the educational supervisors and principals of schools and teachers in Al-Namas governorate. A magister message that is not published. College of Education, King Saud University: Riyadh

- Shawq, Mahmoud and Saeed, Mohammed. (2001): The 21st century teacher (his choice - preparation - development) in the light of Islamic trends: Arab Thought House, Cairo.

- Sheikh, Omar. (2002). (Teacher for the 21st Century in Jordanian School and the Challenges of the 21st Century) Abdul Hameed Shoman Foundation, Amman, Jordan.

- The Ministry of Education. (2009). The project of developing mathematics and natural sciences. Riyadh. Obeikan Research \& Development. 
